\title{
DINÂMICA DA REGENERAÇÃO NATURAL DE Vouacapoua americana COM DIÂMETRO <5 CM, INFLUENCIADA POR CLAREIRAS, EM MOJU,PARÁ
}

\author{
César Augusto Nunes dos Santos ${ }^{1}$, Fernando Cristóvam da Silva Jardim² \\ ${ }^{1}$ Eng. Florestal, M.Sc., Secretaria Estadual de Meio Ambiente (SEMA), Belém, PA, Brasil - cesarnsantos@ yahoo.com.br \\ ${ }^{2}$ Eng. Florestal, Dr., Instituto de Ciências Agrárias, UFRA, Belém, PA, Brasil - fernando.jardim@ufra.edu.br \\ Recebido para publicação: 19/07/2010 - Aceito para publicação: 30/06/2012
}

\begin{abstract}
Resumo
Avaliou-se a dinâmica da regeneração natural de Vouacapoua americana Aubl. influenciada por clareiras, através de ingresso e mortalidade, em floresta explorada seletivamente no campo experimental da Embrapa - Amazônia Oriental, em Moju, Pará. Nove clareiras provenientes da exploração, variando de $231 \mathrm{~m}^{2}$ a $748 \mathrm{~m}^{2}$ de área, foram estudadas. A partir da borda de cada clareira, foram marcadas quatro faixas de $10 \mathrm{~m}$ x 50m nas direções norte, sul, leste e oeste. Para avaliação da regeneração natural da espécie, dentro de cada faixa foram implantadas três subparcelas de $2 \mathrm{~m} \times 2 \mathrm{~m}$, na borda da clareira, e nas distâncias de $20 \mathrm{~m}$ e $40 \mathrm{~m}$, respectivamente, em relação à borda da clareira. Foram utilizados os modelos matemáticos de taxas de regeneração natural (TR\%), de ingresso (I\%) e de mortalidade (M\%), cujos valores não apresentaram diferença estatística significativa, tanto em relação às distâncias da clareira como nas direções cardinais e em relação ao tempo de monitoramento. Os resultados obtidos mostraram que a espécie em estudo apresentou alta mortalidade e baixo ingresso, sendo que, no final dos dez anos de monitoramento, a taxa de regeneração natural apresentou-se negativa. Vouacapoua americana Aubl., no geral, mostrou comportamento ecológico compatível ao grupo ecológico de espécies intermediárias.

Palavras-chave: Amazônia; florestas tropicais; manejo florestal; ingresso; mortalidade.
\end{abstract}

\begin{abstract}
Natural regeneration dynamics of Vouacapoua americana with diameter $<5 \mathrm{~cm}$, influenced by gaps in Moju, Pará. The dynamic of Vouacapoua Americana Aubl. regeneration under gaps influence was evaluated using ingrowth and mortality rates, in a selectively logged forest in the Experimental Station of Embrapa - Amazonia Oriental, Moju - Pará. Nine gaps proceeding from logging, varying between $231 \mathrm{~m}^{2}$ and $748 \mathrm{~m}^{2}$ were studied. From the edge of each one four transects of $10 \mathrm{~m}$ x $50 \mathrm{~m}$ were placed in North, South, East and West directions. To evaluate the natural regeneration of the three species $2 \mathrm{~m}$ X $2 \mathrm{~m}$ subplots were established in each transect, in the gap border and in distances of $20 \mathrm{~m}$ and $40 \mathrm{~m}$ from the gap border. The Natural Regeneration rate (TR\%), ingrowth (I\%) and mortality (M\%) were used to evaluate the dynamic of $V$. americana and these values did not differ statistically in relation to distances from the gap, in relation to the directions and in relation to time of monitoring. The results revealed high mortality, low recruitment rate and in ten years of monitoring, the natural regeneration rate revealed negative. Vouacapoua Americana Aubl., in general, it presented ecological behavior similar to intermediary species group.

Keywords: Amazonia; tropical forests; forest management; ingrowth; mortality.
\end{abstract}

\section{INTRODUÇÃO}

A floresta tropical, por ser um ecossistema complexo, é um grande desafio para a ciência florestal. Há necessidade do conhecimento sobre esse ecossistema, uma vez que ele é submetido a permanentes intervenções, em diversos níveis de intensidade e sem a devida preocupação com sua conservação.

Muitos remanescentes desse ecossistema encontram-se em fase de sucessão natural secundária, fragmentados, alterados e empobrecidos. Mesmo sofrendo grande perturbação, esses povoamentos são um valioso recurso natural renovável, que pode ser utilizado pelas gerações presentes e futuras, via 
conservação através de sua regeneração natural. Por isso, os conhecimentos dos processos de dinâmica de sucessão, regeneração natural e crescimento são fundamentais para a sua utilização (SOUZA et al., 2002).

Parece ser consenso que toda a dinâmica da floresta tropical é dependente da formação de clareiras oriundas de queda de árvores ou de parte delas. Esses distúrbios, portanto, são o principal fator responsável pela composição florística e crescimento da vegetação na floresta tropical (JARDIM et al., 2007).

A sustentabilidade é um dos paradigmas dos planos de manejo, daí a necessidade de estudos acerca da dinâmica populacional das espécies, bem como do processo dinâmico de recomposição e reestruturação da floresta, além de sua composição florística e diversidade (COSTA et al.,1998).

Buscando ampliar os conhecimentos sobre o assunto e contribuir com informações básicas sobre esse complexo ecossistema, esta pesquisa tem como objetivo avaliar a dinâmica dos indivíduos jovens da regeneração natural, com altura total (HT) $\geq 10 \mathrm{~cm}$ e diâmetro $<5 \mathrm{~cm}$, de Vouacapoua americana Aubl. sob a influência de clareiras, por meio da determinação da taxa de regeneração natural (TR\%), ingresso (I\%) e mortalidade (M\%), em áreas de floresta tropical úmida, influenciadas por clareiras, no município de Moju, estado do Pará.

\section{REVISÃO DE LITERATURA}

\section{Conceito e formação das clareiras}

Clareira é a área da floresta com dossel descontínuo, aberta pela queda de galhos de uma ou mais árvores, limitada pela copa das árvores marginais (CARVALHO, 1999). Brokaw (1982) definiu clareira como os autores citados acima, porém, para ele, ela se estende através de todos os estratos de floresta até uma altura média de dois metros do solo.

As clareiras que ocorrem nas florestas tropicais são causadas por distúrbios, na maioria das vezes, de origem natural, mas, também, ocasionados pela ação do homem. Tal evento é conceituado pela maioria dos autores como uma abertura no dossel florestal, existindo variações entre eles quanto à conceituação. Vários estudos têm sido realizados nesses ambientes (HARTSHORN, 1978; ORIANS, 1982; JARDIM et al., 1993), visando o entendimento da dinâmica florestal através do comportamento de espécies florestais nesses distúrbios.

\section{A regeneração natural sob influência das clareiras}

Embora esteja em dinâmica contínua, há um equilíbrio nas florestas naturais, com as árvores mortas sendo continuamente substituídas por novos indivíduos (JARDIM, 1990). Essa constante renovação é observada através dos mosaicos de vegetação em diferentes fases sucessionais, em virtude da ocorrência das clareiras. Seguindo esse critério de avaliação, muitos pesquisadores (SILVA et al., 1995; JARDIM, 1995; AMÉZQUITA, 1998; SERRÃO et al., 2003; MORY, 2000; NEMER et al., 2002) têm estudado o comportamento de espécies de florestas tropicais em clareiras naturais e artificiais, como possível forma de obtenção de informações que irão subsidiar a implementação do manejo florestal.

Por meio desses estudos, constata-se que a ocorrência de distúrbios nessas florestas tem papel importante na dinâmica do recrutamento de plântulas, favorecendo a regeneração natural das espécies (CINTRA, 1998). Tem sido observado que espécies de reconhecido valor comercial apresentam maior crescimento em áreas com dossel aberto, talvez em decorrência da afinidade por luz direta dessas espécies (CARVALHO, 1999). Observa-se, também, um aumento no número dessas espécies nessas áreas (JARDIM et al., 1993; ARAÚJO et al., 2001).

Segundo Jardim (1995), em condições não perturbadas, tanto espécies comerciais quanto não comerciais apresentaram taxa de regeneração natural negativa. Mesquita (1998) comprovou que ocorreu aceleração do crescimento e aumento da sobrevivência de espécies nas áreas manejadas. Outros estudos (JARDIM, 1995) também comprovam que a abertura do dossel é benéfica para muitas espécies florestais. Resta saber o nível de abertura que deve ser aplicado, uma vez que o grau de abertura do dossel pode favorecer mais o ingresso do que o crescimento de árvores remanescentes ou ocorrer reações adversas, dependendo da abertura e da espécie avaliada, desde o crescimento das espécies lá existentes até a mortalidade em massa desses indivíduos (FERREIRA et al., 1998).

\section{Dinâmica florestal}

A dinâmica da floresta tropical é um processo regulado pela formação de clareiras de vários tamanhos, as quais determinam um gradiente complexo de condições microclimáticas. Nesse ambiente, 
cada espécie encontra a faixa ecofisiológica ideal para cumprir seu metabolismo (JARDIM et al., 1993), o que é essencial na formação estrutural das comunidades. O tipo e a intensidade do distúrbio da terra que ocorre nas diferentes regiões alteradas representam influência no padrão de recuperação natural do ecossistema (ARAÚJO et al., 2001).

Whitmore (1989) relata que o banco de sementes do solo abriga, basicamente, sementes de espécies pioneiras e secundárias iniciais, sendo fator essencial para a regeneração da primeira fase de ocupação e cicatrização de grandes clareiras. Essas espécies são representadas por árvores, arbustos e ervas e são comuns como forma de vida predominante do banco de sementes do solo, permanecendo aptas a germinar, por muito tempo, em resposta às alterações na floresta (BAZZAZ; PICKETT, 1980).

Por meio do conhecimento da dinâmica populacional, pode-se avaliar até que ponto as intervenções silviculturais podem influenciar o crescimento das espécies florestais (SOUZA; JARDIM, 1993). Nas florestas, o processo de regeneração natural, em seu sentido estrito, compreende o mecanismo autógeno de perpetuação de suas espécies arbóreas. No sentido técnico, esse processo é uma forma de reconstituir ou perpetuar povoamentos florestais através da disseminação de sementes e do banco de plântulas (INOUE, 1979).

No processo de regeneração da floresta, a geração de novos indivíduos se dá através de propágulos oriundos da dispersão (chuva de sementes), pelo banco de sementes ou plântulas ou ainda a partir da reprodução vegetativa (RODRIGUES et al., 2004). Por isso, o estudo da regeneração natural em florestas tropicais é obrigatório para uma elaboração e aplicação correta dos planos de manejo sustentável, pois a análise permite que se façam deduções sobre a origem da floresta e suas características sócio ecológicas, bem como prevê o seu futuro desenvolvimento e aproveitamento (CARVALHO, 1999). No estudo da dinâmica de populações, busca-se a compreensão das mudanças que ocorrem na estrutura e composição florística de povoamentos ao longo do tempo nas florestas tropicais, sendo relevante a realização de estudos de ingressos, mortalidade e crescimento (SOLOMON, 1980).

$\mathrm{O}$ ingresso ou recrutamento representa o número de árvores que surgem, pela primeira vez, em classes de diâmetro, em dado intervalo de tempo (CONDIT et al., 1994). Do ponto de vista silvicultural, realizar estudos da taxa de ingresso é muito importante, devido à sustentabilidade de uma floresta ser mantida ou "alimentada" regularmente por uma quantidade equilibrada de regeneração natural das espécies florestais (SOLOMON, 1980).

A mortalidade refere-se à morte dos indivíduos na população, definindo-se como o número de indivíduos que morrem num dado período (óbitos por unidades de tempo), ou como a taxa específica em termos de unidades da população total ou de qualquer parte desta (ODUM, 1983). A morte de uma árvore geralmente é o resultado de uma complexa interação entre múltiplos fatores, podendo ser classificada de diversas maneiras: bióticas ou abiótica, alogênica ou autogênica e intrínseca ou extrínseca. Há também morte de indivíduos em pé, provavelmente associada à ocorrência de doenças, ataques de cupins e insetos ou então ao processo de senescência natural (BROKAW, 1985).

\section{DESCRIÇÃO GERAL DA ESPÉCIE Vouacapoua americana}

\section{Características botânicas de Vouacapoua americana}

Voиасароиа атеricana pertence a Fabaceae, que é representada por 152 gêneros e aproximadamente 2.800 espécies (LEWIS et al., 2005).São árvores de grande porte, de 30 a 40 metros de altura, ocupando o estrato dominante da floresta, bastante ramificadas, com caule fúlcreo e folhas imparipinadas, de cor verdeclaro e aspecto brilhoso. A inflorescência é rancemosa, com numerosas flores de coloração amarelo-creme. De modo geral, sua floração coincide com o início da estação chuvosa, que acontece no espaço de tempo de janeiro a março. Possuem tronco reto, sulcado, sem presença de sapopemas (ARAGÃO; ALMEIDA, 1997). A síndrome de dispersão é por barocoria. Suas sementes apresentam comportamento recalcitrante e curta viabilidade (SOUZA et al., 2000). É uma espécie de clímax tolerante à sombra, que se instala como secundária tardia no processo de sucessão, atingindo o dossel quando adulta (LOUREIRO et al., 1979). A frutificação é plurianual - "mast-fruiting" -, com ciclos de dois a três anos (SABATIER, 1985). Os frutos são secos e deiscentes, com uma única semente. A dispersão é feita por pequenos roedores, geralmente a curta distância. As sementes enterradas em solos com boa drenagem ou em clareiras têm maior chance de sobrevivência do que as que ficam na superfície do solo ou sob a copa da árvore-mãe (FORGET et al.,1999). Na região de Belém (PA), essa espécie floresce nos meses de janeiro e fevereiro, ou seja, no período chuvoso, e frutifica de abril a maio, sendo polinizada por insetos generalistas (SABATIER, 1985). 


\section{MATERIAL E MÉTODOS}

A área de estudo está localizada no Campo Experimental da Embrapa - Amazônia Oriental, situado no km 34 da Rodovia PA-150, margem esquerda, município de Moju, na microrregião 18 do estado do Pará, distando $34 \mathrm{~km}$ da cidade de Moju (sede do município) e $115 \mathrm{~km}$ da cidade de Belém.

O Campo Experimental está situado entre as coordenadas geográficas de $2^{\circ} 7^{\prime} 57,03^{\prime \prime}$ e $2^{\circ} 18^{\prime} 28,57^{\prime \prime}$ de latitude sul e $48^{\circ} 47^{\prime} 10,92^{\prime \prime}$ e $48^{\circ} 55^{\prime} 0,35^{\prime \prime}$ de longitude oeste do meridiano de Greenwich, possuindo uma área de 1.059 hectares (SANTOS et al., 1985), dentro da qual foi escolhida uma área de 200 ha para a exploração madeireira seletiva.

O clima da região é Ami (quente úmido), segundo a classificação de Köppen, com a temperatura média anual oscilando entre 25 e $27^{\circ} \mathrm{C}$, e a precipitação média anual entre 2000 e $3000 \mathrm{~mm}$, com distribuição irregular e com a ocorrência de dois períodos pluviais, o mais intenso abrangendo os meses de janeiro a junho, concentrando cerca de $70 \%$ da precipitação média anual. A insolação mensal varia entre 148,0 h e 275,8 h (SANTOS et al., 1985).

O relevo é plano, tornando-se suavemente ondulado, com pequenos desnivelamentos que variam de 0 a 3\%, e de 3 a $8 \%$ de declive, respectivamente, onde predominam solos bem drenados, classificados como Latossolos Amarelos e Argissolos Amarelos típicos, com suas fases pedregosas. A cobertura vegetal da região em que foi realizada a pesquisa está representada por duas formações florestais bem definidas: Floresta Equatorial Subperinifóliae Floresta Equatorial Hidrófila de Várzea (SANTOS et al., 2003).

O experimento foi instalado em uma área de 200 ha de floresta tropical primária de terra firme, que sofreu exploração florestal seletiva em 1997, pertencente ao Campo Experimental da Embrapa Oriental. Dessa exploração, originaram-se diversas clareiras, dentre as quais nove foram utilizadas para a realização desta pesquisa, com tamanho variando entre $231 \mathrm{~m}^{2}$ e $748 \mathrm{~m}^{2}$. Com o auxílio de equipamentos topográficos (trena, bússolas, estadias e teodolitos), cada clareira teve o seu centro determinado. De acordo com seus tamanhos, as clareiras foram classificadas como Clareiras Pequenas $\left(200 \mathrm{a} 400 \mathrm{~m}^{2}\right)$, Clareiras Médias $\left(400\right.$ a $\left.600 \mathrm{~m}^{2}\right)$ e Clareiras Grandes $\left(>600 \mathrm{~m}^{2}\right)$.

Para a coleta de dados no estudo de regeneração natural, instalaram-se três subparcelas amostrais de $2 \mathrm{~m} \times 2 \mathrm{~m}$ dentro das parcelas de números 1,3 e 5 , cada uma medindo $10 \mathrm{~m}$ x $10 \mathrm{~m}$. A subparcela 1 localiza-se na borda das clareiras e as demais ( 3 e 5), a 20 m e 40 m, respectivamente, nas direções norte, sul, leste e oeste. Outra subparcela idêntica foi instalada no centro das clareiras, para efeito de comparação (Figura 1).

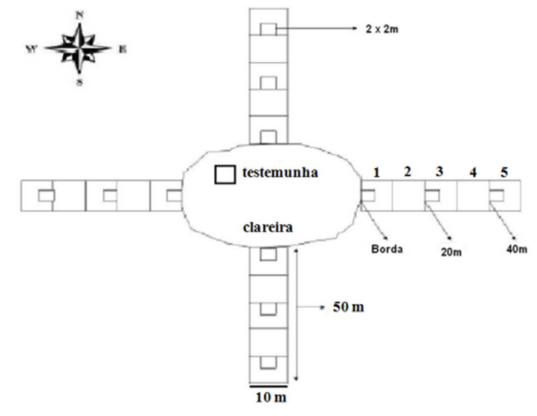

Figura 1. Distribuição das subparcelas amostrais para estudo da regeneração natural de V. americana, no município do Moju, PA.

Figure 1. Sub sample plots distribution for natural regeneration study of $V$. americana, in Moju municipality, State of Para-Brazil.

O comportamento da regeneração natural de Vouacapoua americana foi avaliado pela taxa de regeneração natural (TR\%), através da equação proposta por Mory (2000), a qual é definida como a razão entre a abundância absoluta resultante do processo dinâmico de regeneração natural (recrutamento, mortalidade e crescimento) e a abundância no início do estudo, em percentagem, sendo representada pela expressão:

$$
\operatorname{Tr} \%=\frac{\left(A_{1}-A_{0}\right)}{\left(A_{1}+A_{0}\right)} \times 100
$$


Em que: $\quad \operatorname{Tr}=$ taxa de regeneração natural;

$\mathrm{A}=$ abundância absoluta;

$\mathrm{A}_{\mathrm{o}}=$ abundância absoluta no início do período;

$\mathrm{A}_{1}=$ abundância absoluta no final do período.

sendo: $\quad \mathrm{A}_{1}=\mathrm{A}_{\mathrm{o}}+\mathrm{ni}-\mathrm{ns}$

Em que: $\quad$ ni = número de indivíduos que ingressaram no estudo;

ns = número de indivíduos que saíram do estudo.

O comportamento do ingresso e da mortalidade de Vоиасароиа americana foi avaliado pelas equações:

$$
\begin{aligned}
I & =\frac{n i}{A o} \times 100 \\
M & =\frac{n m}{A o} \times 100
\end{aligned}
$$

Em que: $\quad \mathrm{I}=$ taxa de ingresso em percentagem;

$\mathrm{M}=$ taxa de mortalidade em percentagem;

$\mathrm{ni}=$ número de indivíduos que ingressaram no estudo;

$\mathrm{nm}=$ número de indivíduos que morreram durante o período.

A dinâmica da regeneração natural de Vouacapoua americana foi avaliada em relação às direções norte, sul, leste e oeste das clareiras, assim como em relação às distâncias do centro das clareiras para o interior da floresta, em três pontos distintos: borda da clareira, a $20 \mathrm{~m}$ e a $40 \mathrm{~m}$ (Figura 1), para o período de dez anos de monitoramento. A análise estatística dos dados foi realizada no programa Bioestat 5.0, através da análise de variância de três fatores (direções, distâncias e o período) sobre a taxa de regeneração natural, ingresso e mortalidade.

$\mathrm{Na}$ análise realizada em relação ao período de dez anos, foi efetuada uma medição a cada ano: o $1^{\circ}$ ano compara março de 1999 com março de 1998, o $2^{\circ}$ ano compara março de 2000 com março de 1999, o $3^{\circ}$ ano compara março de 2001 com março de 2000 e o $4^{\circ}$ ano compara março de 2007 com março de 2001. Por fim, a análise de dez anos compara março de 2007 com março de 1998.

\section{RESULTADOS E DISCUSSÃO}

Taxa de regeneração natural de Vouacapoua americana

Os resultados da análise de variância dos dados referentes à taxa de regeneração natural (TR) de Vouacapoua americana por direção e por distância, e o comportamento durante 10 anos de monitoramento, em áreas de floresta influenciada por clareiras, no município de Moju (PA), mostram que, estatisticamente, não houve influência significativa desses fatores sobre a TR dessa espécie, para o nível de significância de 5\%. No entanto, verifica-se que essa taxa se manteve negativa tanto nas direções (Figura 2), excetuando a direção oeste, como nas distâncias (Figura 3) e, também, no monitoramento de dez anos (Figura 4). A direção oeste apresentou a TR positiva de $100 \%$, significando que, nessa direção, houve apenas recrutamento de indivíduos, tendendo, no geral, à estabilização, à medida que se afasta das clareiras e adentra a floresta.

Embora os valores obtidos nas direções norte, sul, leste e oeste não apresentem diferença significativa em nível de 5\%, quando comparados estatisticamente entre si, nota-se que, na direção oeste, a TR é positiva de valor 100\% (Figura 2), verificando-se somente recrutamento e ausência de mortalidade nessa direção. 


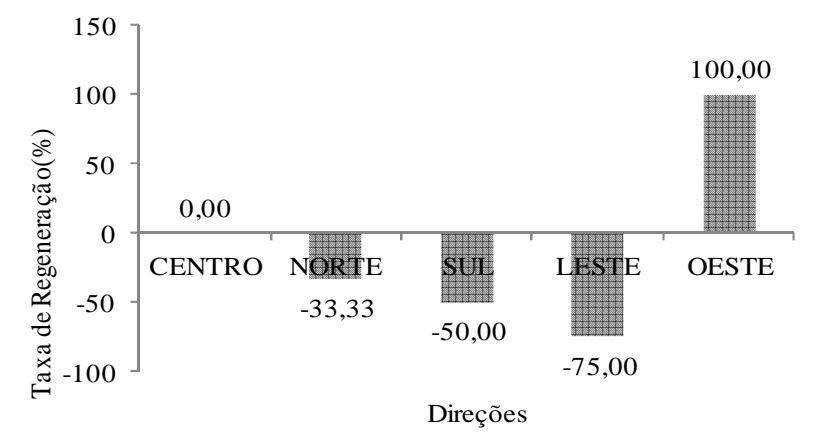

Figura 2. Taxa de regeneração (\%) de Vouacapoua americana nas direções norte, sul, leste e oeste, em áreas de floresta influenciada por clareiras, no município de Moju, PA.

Figure 2. Regeneration Rate (\%) of Vouacapoua americana in North, South, East and West directions, in forest areas influenced by gaps, in Moju municipality, State of Para, Brazil.

A TR de Vоиасароиа americana, de modo geral, apresentou valores negativos. A menor taxa foi de $-75,00 \%$ na direção leste e a maior na direção oeste, com 100\%. Os resultados obtidos nos dez anos de monitoramento indicam que houve maior número de indivíduos mortos do que recrutamento, permitindo deduzir que a radiação solar no centro da clareira não favoreceu a germinação e o crescimento da espécie nessa área. Nenhum indivíduo ocorreu nas parcelas localizadas no centro das clareiras.

De certo modo, Vouacapoua americana regenerou-se um pouco melhor no eixo leste-oeste, onde a radiação é maior e mais rica em termos de radiação fotossinteticamente ativa (PAR) (MALHEIROS, 2001), caracterizando-se como uma espécie pertencente ao grupo ecológico das intermediárias, uma vez que ela se beneficia tanto no eixo de maior abundância de radiação solar quanto em área de menor incidência de radiação solar.

Os valores encontrados para a TR em função das distâncias, estatisticamente, não apresentam diferenças em nível de $5 \%$ de probabilidade. Esses valores decrescem $(-14,29 ;-40,00 ;-81,82)$ à medida que se adentra no sub-bosque (Figura 3).

As TRs, nas distâncias borda de clareira, 20 metros e 40 metros, apresentam-se nitidamente decrescentes à medida que se adentra no interior da floresta. A borda de clareira apresenta uma taxa de regeneração de $-14,29 \%$, e as distâncias 20 metros e 40 metros, valores de $-40,00 \%$ e $-81,82 \%$, respectivamente. Com isso, o conceito de clareira como "uma descontinuidade na cobertura florestal, cuja área engloba toda sua zona de influência até onde houver espécies pioneiras regenerando" (POPMA et al., 1988) tem grande aplicação. Esse resultado indica também que Vouacapoua americana, mesmo sendo classificada no grupo ecológico das espécies tolerantes, não se beneficiou com a oferta de radiação abundante em pelo menos alguma fase do seu estágio inicial.

Martins et al. (2008) realizaram estudos em clareiras de uma floresta estacional semidecidual no município de Viçosa (MG), verificando a ocorrência de espécies se regenerando em ambientes aparentemente desfavoráveis em termos de intensidade luminosa, e registraram a ocorrência de 69 espécies consideradas tolerantes se regenerando em clareiras de diferentes tamanhos.

Esse comportamento pode não ser típico de todas as espécies tolerantes, mas algumas têm demonstrado a capacidade de adaptação em ambientes diversos. Tem sido observado o fato de as espécies tolerantes sobreviverem em ambientes com baixa quantidade de radiação, em vez de se considerar que tenham melhor desempenho em ambientes sombreados. Esse fato ratifica a ideia de que classificar as espécies em grupos ecológicos dicotômicos como heliófilas/umbrófilas é simplista demais. Por isso, realizar estudos para determinar em que nível de radiação essas espécies sobrevivem significa responder à questão de qual é a abertura suportada por essas espécies, particularmente em atividades que promovam abertura do dossel (SERRÃO et al., 2003).

Nemer (2003), ao estudar o comportamento de uma população de Eschweilera odora (Poepp.) Miers, na mesma área deste estudo, notou que não houve qualquer relação ou tendência entre os valores de TR e as direções norte, sul, leste e oeste, tampouco com as distâncias a partir do centro das clareiras, concluindo, dessa forma, que durante o período estudado Eschweilera odora (Poepp.) Miers não 
dependeu dos microambientes provocados pela formação de clareiras para germinar suas sementes, comportando-se como uma espécie tolerante.

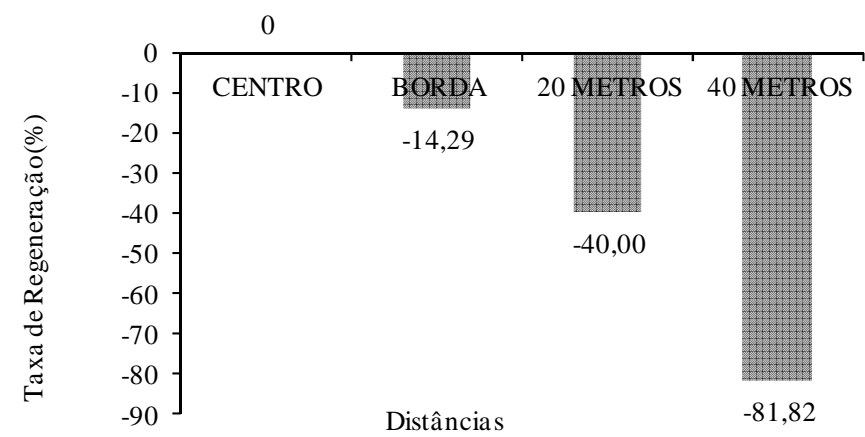

Figura 3. Taxa de regeneração (\%) de Vоиасароиа americana nas distâncias do centro das clareiras, em áreas de floresta influenciada por clareiras, no município de Moju, PA.

Figure 3. Regeneration rate (\%) of Vouacapoua americana in the distances from the gap center, in forest areas influenced by gaps, in Moju municipality, State of Para, Brazil.

Esse comportamento típico de espécies tolerantes de Eschweilera odora (Poepp.) Miers, referido por Nemer (2003), difere do apresentado pela Vouacapoua americana neste estudo, que, embora não apresente diferenças estatísticas na TR, mostrou uma aparente relação decrescente entre essa taxa e o afastamento do centro da clareira para o interior da floresta. A taxa de regeneração expressa o balanço entre recrutamento e mortalidade. Portanto, apesar de ter havido recrutamento, houve predomínio da mortalidade na população da espécie, provavelmente devido à diminuição das condições de luz à medida que a espécie se afasta da clareira.

Espécies tolerantes à sombra se caracterizam pelo contínuo recrutamento, devido à grande disponibilidade de sementes com curto período de viabilidade, não permitindo acúmulo no banco de sementes. Porém apresentam alta mortalidade, principalmente dos menores indivíduos, que têm menos chances competitivas em relação aos maiores, o que justifica sua distribuição decrescente (MORY; JARDIM, 2001). Todavia, o balanço entre recrutamento e mortalidade produz uma grande estabilidade populacional ao longo do tempo, indicada por valores de TR muito próximos de zero (NEMER, 2003).

Estatisticamente, não houve diferença significativa em nível de 5\% de probabilidade nos dez anos de monitoramento. Entretanto, Vouacapoua americana, ao final do período de monitoramento, apresentou TR de $-62,78 \%$ (Figura4), refletindo alta taxa de mortalidade no seu comportamento.

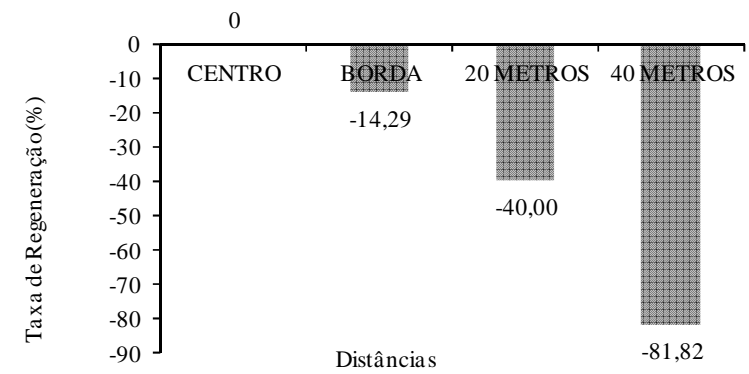

Figura 4. Taxa de regeneração (\%) de Vouacapoua americana nos dez anos de monitoramento, em áreas de floresta influenciada por clareiras, no município de Moju, PA.

Figure 4. Regeneration rate (\%) of Vouacapoua americana during ten years of monitoring, in forest areas influenced by gaps, in Moju municipality, State of Para, Brazil. 


\section{Taxa de ingresso de Vouacapoua americana}

Os resultados da análise de variância de três fatores referentes às taxas de ingresso (\%) de Vouacapoua americana por direção, nas distâncias e durante dez anos de monitoramento, em áreas de floresta influenciada por clareiras, no município de Moju (PA), podem ser visualizados na figura 5, na qual a direção leste se destaca, com $29,51 \%$ de taxa de ingresso, embora, estatisticamente, não haja diferença significativa entre essas taxas em nível de $5 \%$ de probabilidade.

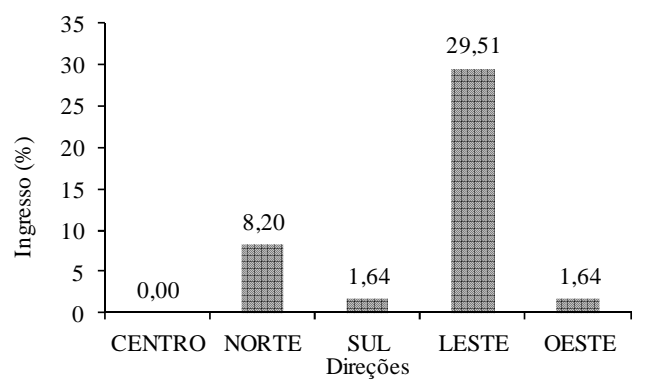

Figura 5. Ingresso (\%) de Vouacapoua americana nas direções norte, sul, leste e oeste, em áreas de floresta influenciada por clareiras, no município de Moju, PA.

Figure 5. Ingrowth(\%) of Vouacapoua americana in North, South, East and West directions, in forest areas influenced by gaps, in Moju municipality, State of Para, Brazil.

Os resultados, estatisticamente, não apresentam diferença significativa em nível de 5\% de probabilidade, destacando-se a distância de 40 metros do centro das clareiras, com 31,15\% de indivíduos recrutados (Figura 6).

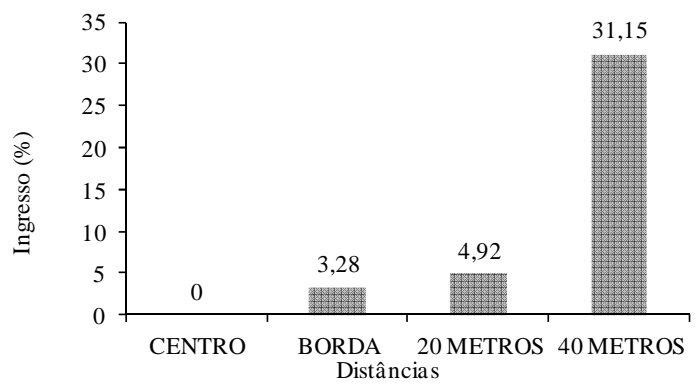

Figura 6. Ingresso (\%) de Vouacapoua americana nas distâncias do centro das clareiras, em áreas de floresta influenciada por clareiras, no município de Moju, PA.

Figure 6. Ingrowth(\%) of Vоиасароиа americana in the distances from the gap center, in forest areas influenced by gaps, in Moju municipality, State of Para, Brazil.

Houve diferença significativa, estatisticamente, em nível de 5\% de probabilidade, nos valores de ingresso em relação ao período de monitoramento (Tabela 3), com destaque altamente significativo no terceiro ano de medição, cujo ingresso foi de $36,07 \%$ (Figura 7).

As taxas de ingresso, nesta pesquisa, apresentam variações de níveis diferentes no seu decorrer, com valores menores em relação à taxa de mortalidade, refletindo diretamente na TR negativa verificada anteriormente.

Taxa de mortalidade de Vouасароиа americana

Os resultados da análise de variância dos dados referentes à taxa de mortalidade (TM\%) de Vouacapoua americana por direção, nas distâncias e durante dez anos de monitoramento, em áreas de floresta influenciada por clareiras, no município de Moju $(\mathrm{Pa})$, mostram que asTMs em relação às direções norte, sul, leste e oeste não apresentaram diferença significativa em nível de $5 \%$ de probabilidade, quando comparadas estatisticamente. Porém, destaca-se a direção leste, que apresentou $68,85 \%$, e a direção oeste, com ausência de mortalidade (Figura 8). 


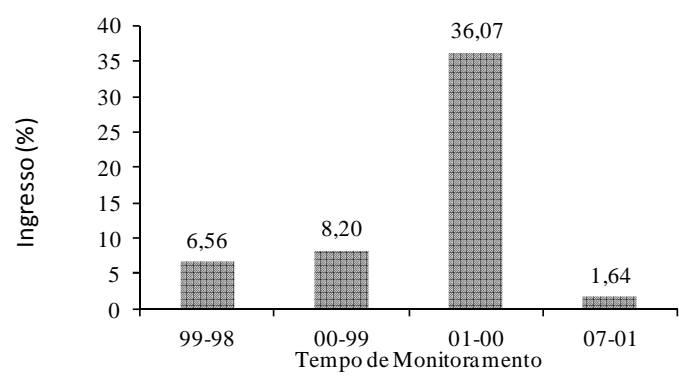

Figura 7. Ingresso (\%) de Vouacapoua americananos dez anos de monitoramento, em áreas de floresta influenciada por clareiras, no município de Moju, PA.

Figure 7. Ingrowth (\%) of Vouacapoua americana during ten years of monitoring, in forest areas influenced by gaps, in Moju municipality, State of Para, Brazil.

Também não houve diferenças significativas em nível de 5\% de probabilidade nos valores de taxa de mortalidade em função das distâncias do centro de clareiras (Tabela 4), contudo verifica-se aumento da mortalidade à medida que se adentra no sub-bosque (Figura 9).

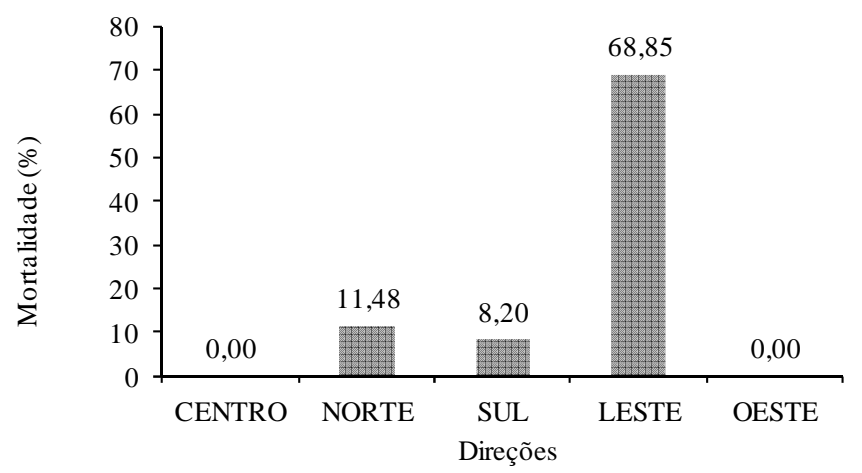

Figura 8. Mortalidade (\%) de Vouacapoua americana nas direções norte, sul, leste e oeste, em áreas de floresta influenciada por clareiras, no município de Moju, PA.

Figure 8. Mortality (\%) of Vouacapoua americanain North, South, East and West directions, in forest areas influenced by gaps, in Moju municipality, State of Para, Brazil.

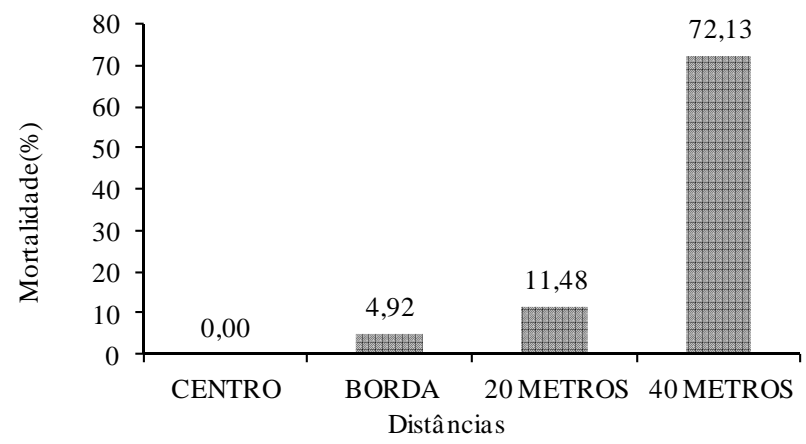

Figura 9. Mortalidade (\%) de Vouacapoua americana nas distâncias do centro das clareiras, em áreas de floresta influenciada por clareiras, no município de Moju, PA.

Figure 9. Mortality (\%) of Vouacapoua americana in the distances from the gap center, in forest areas influenced by gaps, in Moju municipality, State of Para, Brazil. 
As taxas de mortalidade da espécie Vouacapoua americana registradas neste estudo podem ser explicadas pelo fato de que, na área mais distante do centro das clareiras e no período logo após o distúrbio, a mortalidade tende a ser maior. Contudo, nota-se que, à medida que se adentra ao sub-bosque, provavelmente há equilíbrio no processo de sucessão.

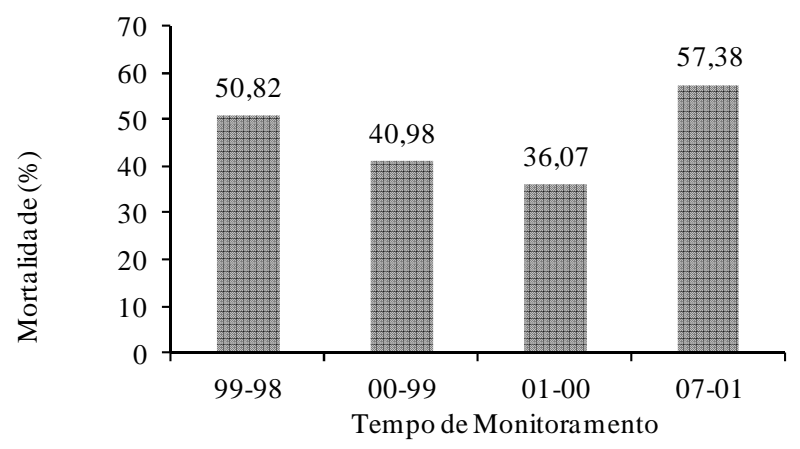

Figura 10. Mortalidade (\%) de Vouacapoua americana nos dez anos de monitoramento, em áreas de floresta influenciada por clareiras, no município de Moju, PA.

Figure 10. Mortality (\%) of Vouacapoua americana during ten years of monitoring, in forest areas influenced by gaps in Moju municipality, State of Para, Brazil.

Essa alta mortalidade na fase inicial de desenvolvimento dos indivíduos é uma das principais características das espécies pertencentes ao grupo ecológico tolerante, pois, para que apresentem uma distribuição diamétrica decrescente ou em forma de "J invertido", é necessário que a mortalidade dos indivíduos seja constante à medida que se aumente a classe diamétrica.

A mortalidade de mudas transplantadas da regeneração natural para clareiras de diferentes tamanhos, nesta mesma área de estudo, variou de $41,1 \%$ a $55,0 \%$, com destaque para Vouacapoua americana $(70,1 \%)$, Jacaranda copaia $(69,1 \%)$ e Newtonia suaveolens $(58,7 \%)$ em clareiras grandes (JARDIM et al., 2007). Essa alta mortalidade pode confirmar as afirmações de que plântulas e mudas já estabelecidas podem crescer pouco, ou mesmo morrer, em virtude da alta carga de radiação (WHITMORE, 1978).

Resultados diferentes foram encontrados em pesquisa em floresta próxima de Manaus, no estado do Amazonas, onde se verificou que o ingresso ou recrutamento cresceu com o decorrer do tempo na floresta explorada e que a mortalidade, ainda que mais baixa que o ingresso, foi muito alta logo após a exploração, reduzindo-se significativamente até o quinto ano após a exploração e mantendo-se com taxas baixas até o final do período estudado (CARVALHO, 1999).

\section{CONCLUSÕES}

- A regeneração natural de Vouacapoua americana não foi favorecida pela intensa radiação solar que ocorre no centro das clareiras, uma vez que a taxa de regeneração natural foi negativa ao final dos dez anos de monitoramento após a exploração florestal de impacto reduzido, consequência de uma mortalidade maior que o recrutamento de indivíduos jovens. Em virtude desse comportamento, a espécie deve merecer especial atenção quando do estabelecimento de planos de manejo florestal, para evitar o comprometimento de sua sobrevivência na área de manejo.

- Além disso, observou-se que os indivíduos jovens da espécie Vouacapoua americana não são favorecidos em áreas de clareiras, apresentando uma intensa flutuação, com períodos alternados de alta mortalidade e baixo ingresso, ou seja, saldo negativo refletido em sua regeneração natural. Assim, a pesquisa mostra que a espécie em análise, mesmo sendo classificada no grupo ecológico das espécies tolerantes, não se beneficiou com a oferta de radiação abundante, em pelo menos alguma fase do seu estágio inicial. 


\section{REFERÊNCIAS}

AMÉZQUITA, P. Light environment affects seedlings performance in Psicotriaaubletiana (Rubiaceae), a tropical understory shrub. Biotropica, v. 30, n. 1, p. 126 - 129, 1998.

ARAGÃO, I. L. G.; ALMEIDA, S. S. Estrutura ecológica comparada de populações de acapu (Vouacapoua americana Aubl., Caesalpiniaceae) em duas florestas de terra firme na Amazônia Oriental. In: Lisboa, P. L. B. org. Caxiuanã. Belém: Museu Paraense Emílio Goeldi, v. I, p. 273 - 290, 1997.

ARAÚJO, M. M.; OliveirA, F. A. I. C. G.; BARroS, P. L. C.; LiMA, C. A. T. Densidade e composição florística do banco de sementes do solo de florestas sucessionais na região do Baixo Rio Guamá Amazônia Oriental. Scientia Forestalis, n. 59, v. 12, p. 115 - 130, 2001.

BAZZAZ, F. A.; PICKETT, S. T. A. Physiological ecology of tropical succession: a comparative review. Annual review on ecology and systematic, v. 15, n. 11, p. 287 - 310, 1980.

BROKAW, N. V. L. The definition of tree fall gap and its effect on measure of forests dynamics. Biotropica, v. 14, n. 2, p. 156 - 160, 1982.

Treefalls, regrowth, and community structure in tropical forests. In: S. T. A. Pickett, P. S. White. The ecology of natural disturbance and patch dynamics. London: Academic Press, p. 53 - 69. 1985.

CARVALHO, J. O. P. de. Dinâmica de florestas naturais e sua implicação para o manejo florestal. In: Simpósio silvicultural na Amazônia Oriental: Contribuições do projeto EMBRAPA/DFID. Belém-Pará. Fevereiro. Resumos expandidos. p. 174 - 179. 1999.

CINTRA, R. 1998. Sobrevivência pós-dispersão de sementes e plântulas de três palmeiras em relação à presença de componentes da complexidade estrutural da floresta amazônica. In: GASCON, C.; MOUTINHO, P. (eds.). Floresta amazônica: dinâmica, regeneração e manejo. p. 83 - 98. INPA-Manaus. $373 \mathrm{p}$.

CONDIT, R.; HUBBEL, S. P.; FOSTER, R. B. Density dependence in two understory tree species in a neotropical forest. Ecology Oxford, v. 75, n. 3, p. 671 - 680, 1994.

COSTA, D.H.; FERREIRA, C. A. P.; SIlVA, J. N. M.; LOPES J do C. A.; CARVALHO, J. O. P. Potencial madeireiro de floresta densa no município de Moju, estado do Pará. Belém: Embrapa CPATU, Documentos 121. 33 p. 1998.

FERREIRA, R. L. C.; SOUZA, A. L. de; DE JESUS, R. M. Ingresso e mortalidade em uma floresta secundária de transição. Revista Árvore, Viçosa, v. 22, n. 2. p. 155 - 162, 1998.

FORGET, P. M.; MERCIER, F.; COLLINET, F. Spatial patterns of two rodent-dispersed rain forest trees Carapaprocera (Meliaceae) and Vouacapouaamericana (Caesalpiniaceae) at Paracou, French Guiana. Journal of Tropical Ecology, Cambridge, v. 15, p. 301 - 313, 1999.

HARTSHORN, G. S. Neotropical forest dynamics. Biotropica, v. 12, p. 30 - 32. Suplemento, 1978.

INOUE, M. T. Regeneração natural: seus problemas e perspectivas para as florestas brasileiras. Curitiba: FUPEF, p. 23, 1979. (Série Técnica, 1)

JARDIM, F. C. da S. Mortalidade e crescimento na floresta equatorial de terra firme. Boletim do Museu Paraense Emílio Goeldi, v. 6, n. 2, p. 227 - 234, dez. 1990.

Comportamento da regeneração natural de espécies arbóreas em diferentes intensidades de desbastespor anelamento na região de Manaus - AM. 1995. f. 169. Tese (Doutorado em Ciências Florestais) - Universidade Federal de Viçosa, Minas Gerais, 1995.

JARDIM, F. C. da S.; HOSOKAWA, R. T. Estrutura da floresta equatorial úmida da Estação Experimental de Silvicultura Tropical do INPA. Acta Amazônica, v. 16/17, n. único, p. 411 - 508, 1986 - 1987. 
JARDIM, F. C. da S.; SERRÃO, D. R.; NEMER, T. C. Efeito de diferentes tamanhos de clareiras sobre o crescimento e a mortalidade de espécies arbóreas em Moju - PA. Acta Amazônica, v. 37, p. 37 - 38, 2007.

JARDIM, F. C. da S.; VOLPATO, M. M. L.; SOUZA, A. L. Dinâmica de sucessão natural em clareiras de florestas tropicais. Viçosa: SIF, p. 60. (Documento SIF, 010), 1993.

LEWIS, G. P; SCHRIRE, B. D.; MACKINDER, B.; LOCK, M. Legumes of the World. Royal BotanicGardens, KEW, p. 577, 2005.

LOUREIRO, A. A.; SILVA, M. F.; ALENCAR, J. da C. Essências madeireiras da Amazônia. Manaus, AM: INPA, 187 p., v. I, 1979.

MALHEIROS, M. A. B. Caracterização do fluxo de radiação fotossinteticamente ativa, irradiância espectral e relação vermelho: vermelho extremo em clareiras da exploração florestal seletiva, em Moju, Pará, Brasil. 2001. 93 f. Dissertação (Mestrado) - Faculdade de Ciências Agrárias do Pará, Belém, 2001.

MARTINS, S. V.; GLERIANI, J. M.; AMARAL, C. H. do; RIBEIRO, T. M. Caracterização do dossel e do estrato de regeneração natural no sub-bosque e em clareiras de uma florestal estacional semidecidual no município de Viçosa, MG. Revista Árvore, v. 32, n. 4, p. 759 - 767, 2008.

MESQUITA, R. de C. G. O impacto da remoção do dossel de uma mata secundária no crescimento de duas espécies de interesse econômico da Amazônia. In: GASCON, C.; MOUTINHO, P. (eds.). Floresta Amazônica: dinâmica, regeneração e manejo. Manaus: INPA, p. 261 - 274, 1998.

MORY, A. de M. Comportamento de espécies arbóreas em diferentes níveis de desbaste por anelamento. 100 p. Dissertação (Mestrado em Ciências Florestais) - FCAP, Belém, Pará, 2000.

MORY, A. de M.; JARDIM, F. C. da S. Comportamento de Eschweilera odora (Poepp.) Miers (matamata-branco) em diferentes níveis de desbaste por anelamento. Revista de Ciências Agrárias, Belém, n.36, p. 29 - 53, 2001.

NEMER, T. C. Dinâmica da população de Eschweilera odora (Poepp.) Miers (matamata-branco) em floresta tropical de terra firme manejada, Moju, Pará, Brasil. 76 p. Dissertação (Mestrado em Ciências Florestais) - Universidade Federal Rural da Amazônia, 2003.

NEMER, T. C.; JARDIM, F. C. da S.; SERRÃO, D. R. Sobrevivência de mudas da regeneração natural de espécies arbóreas três meses após o plantio, em clareiras de diferentes tamanhos. Revista Árvore, v. 26, p. $217-221,2002$.

ODUM, E. P. Ecologia. Atlanta, University of Georgia, p. 434, 1983.

ORIANS, G. H. The influence of tree-fall in Tropical Forest in Tree SpeciesRichness.Tropical Ecology. v. 23 , n. 2, p. 255 - $279,1982$.

POPMA, J.; BONGERS, F.; MARTINEZ-RAMOS, M.; VENEKLASS, A. Pioneer species distribution in treefall gaps in neotropical rain forest; a gap definition and its consequences. Journal of Tropical Ecology, v. 4, p. 77 - 88, 1988.

RODRIGUES, R. R.; MARTINS, S. V.; BARROS, L. C. Tropical rainforest regeneration in an area degraded by mining in Mato Grosso State, Brazil. Forest Ecology and Management. v. 190, p.323 - 333, 2004.

SABATIER, D. Saisonnalité et déterminisme du pic de fructification en ferêtguyanaise. Revue d'Ecologie, v. 2, n. 40, p. 289 - 320, 1985.

SANTOS, P. L. dos; SILVA, J. M. L. da; SILVA, B. N. R. da; SANTOS, R. D. dos; REGO, G. S. Levantamento semidetalhado dos solos e avaliação da aptidão agrícola das terras para culturas de dendê e seringueira. Projeto Moju, Pará. Relatório Técnico. Rio de Janeiro: Embrapa/SNLCS. 192 p. 1985.

SANTOS, P. L. dos; SILVA, J. M. L. da; SILVA, B. N. R. da; SANTOS, R. D. dos; REGO, G. S. Caracterização e potencialidade dos solos do Campo Experimental de Moju. Belém: Governo do estado do Pará, 2003. 
SERRÃO, D. R.; JARDIM, F. C. da S.; NEMER, T. C. Sobrevivência de seis espécies florestais em uma área explorada seletivamente no município de Moju- Pará. Revista Cerne, Lavras - MG, v. 9, n. 2, p. 153 $-163,2003$.

SILVA,J. N. M.; CARVALHO,J. O. P.; LOPES,J. do C. A.; ALMEIDA,B. F. de; COSTA, D. H. M.; OLIVEIRA, L. C. de; VANCLAY, J. K.; SKOVSGAARD, J. P. 1995. Growth and yield of a tropical rain forest in the Brazilian Amazon 13 years after logging. Forest Ecologyand Management.v. 71, n. 3, 267 - 274.

SOLOMON, M. E. Dinâmica de populações. São Paulo: EPU, p. 78, 1980.

SOUZA,A. L.; JARDIM,F. C. da S. Sistemas silviculturais aplicáveis nas florestas tropicais. Viçosa, SIF, 1993. 125 p. (Documento SIF, 008).

SOUZA, A. L.;SCHETTINO, S.;JESUS, R. M. de; VALE, A. B. do. Dinâmica da regeneração natural em uma Floresta Ombrófila Densa Secundária após corte de cipós, Reserva Natural da Companhia Vale do Rio Doce S. A., estado do Espírito Santo, Brasil. Revista Árvore, v. 26, n. 4, p. 411 - 419, 2002.

WHITMORE,T. C. Gaps in the forest canopy. In: Tomlinson,Zimmerman (eds.). Tropical trees asliving systems. London,Cambridge Univ. Press, 1978. p. 639 - 655.

. Canopy gaps and two major groups of forest trees. Ecology, v. 70, n. 3, p. 536 - 538, 1989. 
FLORESTA, Curitiba, PR, v. 42, n. 3, p. 495 - 508, jul./set. 2012.

Santos, C. A. N. dos, Jardim, F. C. da S. 